\title{
The Performance Consequences of Top Management Successions
}

\author{
THE ROLES OF ORGANIZATIONAL \\ AND ENVIRONMENTAL CONTEXTS
}

\author{
ZHIANG LIN \\ DAN LI \\ University of Texas at Dallas
}

\begin{abstract}
As an exploratory step toward integrating differing views in the field of top management succession, this study takes an open system's perspective and examines the effect of top management succession on organizational performance, in particular decision-making accuracy, under conditions where various organizational and environmental factors can interact. Through a formal computer simulation model that captures the basic behaviors of human decision making and the fundamental characteristics of organizational and environmental settings, the results show that whether top management successions may affect organizational performance, and if so, how organizational performance may be affected, depends on such contextual variables as industry environment, organizational structure, succession type, and organizational age. This study has also demonstrated the importance of moving toward a more systematic and precise contingency approach and the power of computer modeling in understanding the multilevel process of top management succession in complex and dynamic organizations.
\end{abstract}

Keywords: top management succession; open system's perspective; multilevel approach; and computer simulation

The past two decades have witnessed an increasing interest in the topic of top management succession (Kesner \& Sebora, 1994). Studies in this area have ranged from antecedents for top management successions (Dalton \& Kesner, 1985) to characteristics distinguishing insider from outsider successions (Goodstein \& Boeker, 1991; Zajac, 1990) and further to the effect of such successions on market indicators such as stock prices and shareholder reactions (Davidson, Worrell, \& Dutia, 1993; Worrell, Davidson, \& Glascock, 1993). There is, however, an alarming lack of systematic consideration

Thanks go to the editor and two anonymous reviewers for their constructive comments on earlier versions of the manuscript. Editorial help from Linda Robertson is also acknowledged.

Group \& Organization Management, Vol. 29 No. 1, February 2004 32-66

DOI: $10.1177 / 1059601103252092$

(C) 2004 Sage Publications

32 
of the broad organizational and environmental context (Datta \& Rajagopalan, 1998). Additionally, only limited attention has been paid to the impact of top management successions on organizations' performance in making strategic decisions, which we believe is critical for understanding effective organizational operations (Scott, 1987).

This study will attempt to extend prior research by relying on an open system's perspective and using a special methodology-computer modeling. We focus on the multilevel processes of organizations and treat organizations as adaptive open systems. Our interest is not in the factors that contribute to top management successions. Rather, we are interested in the effect of such successions on organizational performance, that is, decision-making accuracy and the situations under which important contingency factors such as external environment, organizational structure, succession type, and organizational age may matter.

By modeling the essence of human decision-making behavior and focusing on the contrasting effects of contingency factors of research interest, we hope findings from this study can shed new light on future research in top management successions and potentially help bridge different views in the field.

\section{STATE OF PRIOR RESEARCH}

Top management succession is a critical organizational decision (Datta \& Rajagopalan, 1998; Hambrick \& Mason, 1984). The selection of personnel to fill such a position in the event of a top management change has been studied extensively in the areas of organization theory, strategic management, and strategic human resources management (Datta \& Rajagopalan, 1998; Miller, 1993). Many researchers have paid great attention to antecedents for top management successions ranging from performance conditions (Dalton \& Kesner, 1985; Datta \& Guthrie, 1994) to deaths of top executives (Worrell \& Davidson, 1987; Worrell, Davidson, Chandy, \& Garrison, 1988), as they believe the preconditions of organizations are important for understanding why organizations change their top managers. Some others, on the other hand, have focused on the different characteristics between insiders and outsiders for top management successions (Goodstein \& Boeker, 1991; Zajac, 1990), as these are not only the two most common types of succession but also may have different consequences for organizations, even though the latter is often not fully studied. Some scholars have further explored the symbolic reason for organizations' selecting specific types of successors (Gifford, 1997; Hannan \& Freeman, 1989; Lieberson \& O'Connor, 1972). 
Then there are other researchers who have shown interest in the effect of top management succession on organizations, although mostly through market and shareholders reactions such as stock prices (Beatty \& Zajac, 1987; Davidson et al., 1993; Worrell et al., 1993).

In this study we are interested in the impact of top management succession on organizational performance, in particular the outcome of decision making. Research on the impact of top management succession on organizations has provided some fragmented and even inconsistent views (Haveman, 1993; Kesner \& Dalton, 1994). The first view believes that a top manager is vital to an organization's success and that top management successions can bring positive changes to organizations. Scholars of this view have generally regarded top management succession as an adaptive process that is necessary for a successful organization (Dalton \& Kesner, 1985; Helmich, 1974; Helmich \& Brown, 1972). They argue that top management successions can reduce conflict and provide a conduit for external information, which enables an organization to become better attuned to environmental demands (Guest, 1962; Helmich, 1974; Pfeffer \& Salancik, 1977, 1978; Singh, House, \& Tucker, 1986; Virany, Tushman, \& Romanelli, 1992) or to signal its intentions to change (Reinganum, 1985). Some of the studies have even shown that up to $40 \%$ of the variance of organizational performance can be explained by such leader changes (Day \& Lord, 1988; Pfeffer \& DavisBlake, 1986; Weiner \& Mahoney, 1981).

Some other studies, however, have found that top management successions have had no effect on organizational performance (Samuelson, Galbraith, \& McGuire, 1985). As some researchers have suggested, there may be a null relationship between succession and organizational performance (Haveman, 1993). Two reasons have been put forward. The first reason focuses on the internal inertia of organizations, in that organizations are often under their environmental and institutional constraints and so executive actions may be limited and managerial impact minimized (Hannan \& Freeman, 1984; White, Smith, \& Barnett, 1997). Scholars of this view have frequently found a lack of empirical support for the impact of top management succession on organizations (Cannella \& Lubatkin, 1993). The second reason argues that the top management succession process is relatively nonadaptive because of the large number of persons and their vested interests involved (Child, 1972; Hannan \& Freeman, 1984, Lieberson \& O'Connor, 1972). Even though environment may be dynamic, organizations, particularly the large ones, tend to resist change, due to self-interests of the parties involved, organizational politics such as scapegoating (Gamson \& Scotch, 1964), and power distribution (Ocasio, 1994). 
Then, there is the vicious circle view, which believes that top management changes can only add disruptions to the organization, thus worsening the performance (Cannella \& Lubatkin, 1993; Grusky, 1963). For example, Friedman and Singh (1989) have suggested that top management succession may result in two types of disruptions: destroying the fit between the organization and its environment and disrupting its internal authority structure. Both disruptions are believed to decrease organizational performance.

The above brief review has revealed a fragmented field with a serious lack of systematic consideration of the broad environmental and organizational context including external environment, organizational structure, succession type, and organizational age. An increasing number of scholars in the field of top management succession have recognized the importance of contingency factors (Reinganum, 1985). For example, some studies have begun to ask questions of how and when organizational factors may matter in top management successions (Datta \& Rajagopalan, 1998; Friedman \& Singh, 1989). Others have considered firm size and firm R\&D intensity (Guthrie \& Datta, 1997). Some other researchers have begun to explore how organizational factors such as size and growth may play a role in top management successions (Day \& Lord, 1988; Samuelson et al., 1985). However, the outcome variable of these studies is often about the characteristics of top management successors with no further expansion to the fundamental aspect of organizational performance such as decision making. Finally, there are studies that have discussed the importance of matching top management characteristics to industry characteristics (Osborn, Jauch, Martine, \& Glueck, 1981; Pfeffer \& Salancik, 1977; Smith \& White, 1987; J. D. Thompson, 1967). How and what match should be sought and under what conditions, however, have not been fully explored.

\section{AN OPEN SYSTEM'S PERSPECTIVE}

In this study, we take an open system's perspective and argue that the impact of top management succession on organizational performance can only be fully understood with a systematic contingency approach (Lawrence \& Lorsch, 1967; Scott, 1987; J. D. Thompson, 1967). Following many other organizational scholars, we believe that uncertainties, interdependencies, and contingencies in the organizational environment can affect not only the operation of the organization but also the distribution of power and control within the organization, which in turn can influence top management successions (Pfeffer \& Salancik, 1978). With this open system's perspective, the top management succession is no longer an isolated event but a dynamic and 
complex organizational decision process that can be subject to the influences of not only the external environment but also the internal organizational characteristics. Therefore, to fully understand the impact of top management succession on organizational performance, we need to consider the broad organizational and environmental context. In this study, we start out by addressing the following two questions: (a) What, if any, is the impact of top management successions on organizational performance, in particular, decision-making accuracy and (b) what are the respective roles of industry environment, organizational structure, succession type, and organizational age in such top management successions?

\section{INDUSTRY ENVIRONMENT}

Organizations are open systems (J. D. Thompson, 1967). They operate in industry environments that can affect organizations' operations or even survival (Hannan \& Freeman, 1977; Milliken, 1990). Whereas there are multiple characteristics of the industry environment that can affect how organizations respond, one of the most fundamental dimensions has always been whether an industry environment is predictable or unpredictable (Aldrich, 1979; Lin \& Carley, 1997a). A predictable environment features situations where there can be very stable and concentrated customer demands. Organizations can largely rely on institutionalized procedures to deal with organizational problems. As a result, the role of top management may be limited and so the top management succession may not benefit organizational performance. On the other hand, an unpredictable environment features unstable and diverse customer demands, which requires more incremental adaptation by the organization and more individual expertise to tackle the problems (Virany et al., 1992). As a result, top management successions in this environment may have more impact on organizational performance.

Scholars of top management succession have long emphasized the importance of understanding environmental conditions (Lieberson \& O'Connor, 1972; Virany et al., 1992). Tushman and Rosenkopf (1996), for example, have conducted studies on how turbulent and stable environmental contexts may affect the performance outcomes of executive team changes. Specifically, they found that reorganizations at the top level are negatively associated with subsequent performance in stable environments but positively associated with subsequent performance in turbulent environments. Other researchers have also echoed their findings (Guthrie \& Olian, 1991; Schwartz \& Menon, 1985). Based on these, we may have the following hypothesis. 
Hypothesis 1: Industry environment should have a significant effect on an organization's performance change resulting from top management successions. Specifically, an unpredictable environment will have a more positive effect than a predictable environment.

\section{ORGANIZATIONAL STRUCTURE}

Organizations use structures to coordinate members' activities and exert controls (Coleman, 1990; Mintzberg, 1983; Pugh et al., 1963). Although some prior studies on top management succession have discussed limited organizational factors such as size and board composition (Goodstein \& Boeker, 1991), very few have looked beyond the top management position to examine the broader governance structure of a firm (Carroll, 1984). As a result, most studies on top management succession have virtually treated the organization as a black box, with little or no internal structures' being systematically explored.

Although there are different forms of organizational structures (Lin \& Carley, 1997b), it is feasible to limit ourselves to the study of hierarchy versus team structures because the two forms of structures are not only the most studied in management research but also represent the two ends of the structural spectrum (Weick, 1979). These two structures should pose different challenges to top management succession, even though literature has been scarce in that regard (Lin \& Hui, 1999). A hierarchy structure has generally been regarded as one that is based on the premise that individuals' actions should bear limited impact on organizations (Mackenzie, 1978). As institutional theorists believe, organizations design hierarchy structures to limit members' roles and reduce individual members' information processing load so that the reliance on individuals including top managers can be minimized (Pfeffer, 1982; Powell \& DiMaggio, 1991). Therefore, there should be little performance effect due to top management changes.

On the other hand, there are suggestions that a team structure may also limit the impact of top management succession, as a team structure is formed on the concept of consensus building, power sharing, and member versatility (Janis, 1982). As a result, an individual member's turnover may have little impact on the organization as a whole. Based on these considerations, we could expect the following.

Hypothesis 2: Organizational structure in general will have little effect on the change of organizational performance resulting from top management successions. 
However, this pattern may change under different environments as scholars have suggested that different structures may be best suited in different environments (Courtright, Fairhurst, \& Rogers, 1989; J. D. Thompson, 1967). Specifically, a team structure is suggested to be better off in an unpredictable environment as members have better information-processing capability and can help each other with their diverse expertise (Burns \& Stalker, 1961). On the other hand, for a hierarchy organization, the members' information-processing capability is limited by the design and so may be more suitable for dealing with a predictable industry environment (Hall, 1991; Lawrence \& Lorsch, 1967). As a result, we would expect the following hypothesis.

Hypothesis 3: A hierarchy structure will help top management successions to have a positive impact on organizational performance in a predictable industry environment whereas a team structure will do so in an unpredictable industry environment.

\section{SUCCESSION TYPE}

Researchers have also shown a great interest in two main types of top management successions: internal promotions and external hirings. Numerous studies have underscored the different characteristics for the two types of successions and explored the antecedents to such successions at the top management level (Helmich \& Brown, 1972; Zajac, 1990). Their focus, however, has mostly been on the organizational causes of top management successions for triggering different types of successions (Dalton \& Kesner, 1985; Worrell et al., 1988). Oftentimes, the impact of such successions on organizational performance is largely unattended.

In this study, we wish to explore what impact each type of succession may possess on organizational performance. Research in this area has suggested that organizations hoping for much better performance tend to go for external hiring because such a move is expected to bring more dramatic changes in overcoming organizational inertia (White et al., 1997). Some researchers seemed to have confirmed such an assertion in their studies of organizations with a poor initial state (Cannella \& Lubatkin, 1993; Schwartz \& Menon, 1985). However, other studies have shown that oftentimes, organizations take such dramatic approaches not for the performance sake but for symbolic reasons such as finding scapegoats (Boeker, 1992; Hannan \& Freeman, 1989; Lieberson \& O'Connor, 1972) or appeasing stockholders (Worrell et al., 1993). Their argument, based on power and politics, suggests that top management succession is more a political process than an organizational process for performance improvement. Others have also questioned the 
effectiveness of external hirings as they suggest that an external successor's different industry background may impede the potential improvement of organizational performance (Guthrie \& Datta, 1997; Wiersema, 1992). As a result, internal promotions may in general be more beneficial to the organizational performance than external hirings (Lieberson \& O'Connor, 1972; Worrell et al., 1993).

Hypothesis 4: Internal promotions in general tend to have a more positive effect on the change of organizational performance resulting from top management successions than external hirings.

\section{ORGANIZATIONAL AGE}

Another important aspect that is often being overlooked in studies of top management succession is the age of the organization. For this study, we believe prior findings from other organizational fields may be helpful for better understanding the issue of top management succession. Population ecologists, for example, have frequently alerted our attention to the importance of organizational age through such issues as organizational newness and mortality (Carroll, 1984; Singh, Tucker, \& House, 1986). From the perspective that organizations are adaptive systems, we take the position that age is a strong indicator of the accumulated experience and is highly important to organizations (Kimberly \& Miles, 1980; Lant \& Mezias, 1992). We believe top management successions are about the replacement of experiences, whether old or new. Some prior studies have shown the effect of organizational age in the process of organizational changes (Carroll, 1984; Guthrie \& Olian, 1991). One study, for example, has found that the effect of top management successions may be more apparent and positive on young organizations (Greiner and Bhambri, 1989). On the other hand, for more mature organizations, which tend to be more institutionalized and more legitimized with a better track record, top management successions may have little or even negative effect on organizational performance (Hannan \& Freeman, 1977). Given these, we can have the last hypothesis.

Hypothesis 5: Organizational age will have a more positive impact on the change of organizational performance resulting from top management successions in young organizations than in mature organizations.

\section{ORGANIZATIONAL DECISION-MAKING PERFORMANCE}

Organizational performance has been represented by a wide range of indicators. Research has shown that it is impossible to obtain the best or sufficient indicator of organizational performance (Kahn, 1977; Molnar \& Rogers, 
1976) and that whether an organization is said to be effective depends on "the purposes and constraints placed on the organizational effectiveness investigation" (Cameron, 1986). In this study, we examine one aspect of organizational performance, accuracy of decision outcomes (M. D. Cohen, March, \& Olsen, 1972; Hollenbeck, Ilgen, LePine, Colquitt, \& Hedlund, 1998; Lin \& Carley, 1997a). The view of organizational performance from a decisionmaking or problem solving aspect is consistent with the open system's perspective of organizations that emphasizes information processing and problem solving (Hall, 1991; J. D. Thompson, 1967). The importance of decision making cannot be overemphasized. Simon (1947) claims decision making to be the "heart of organizations." Price (1968) regards decision making "the necessity in all organizations." Scott (1987) also considers decision making the basic operation of an organization. Although we understand that organizations may have different performance criteria depending on the nature of their existence, it is our belief that to achieve any kind of success, organizations must make good decisions. How well an organization makes its decisions thus becomes the center of organizational performance.

\section{SUMMARY}

In this research, we take the view that organizations are open systems that can be influenced by the external environments while being constrained by internal structures and other organizational characteristics. Thus, the process of top management succession is an adaptive event that can be affected by the broad environmental and organizational context (Friedman \& Singh, 1989). This approach, albeit reflecting the segmented state of current research on top management succession, shows that there is a limit to pure conceptual thinking on this multilevel issue (House, Rousseau, \& Thomas-Hunt, 1995; Klein, Tosi, \& Cannella, 1999; Simon, 1962). It also creates a springboard leading to the more formal and systematic explorations of the research issues using computer modeling. Figure 1 has depicted the main relationships of these factors.

\section{A FORMAL COMPUTER MODEL}

Organizations are dynamic, complex, and open systems (J. D. Thompson, 1967). To study the impact of top management succession, we must understand the internal dynamic processes and sort out various complex relationships across different levels in organizations. To do so requires a multilevel 


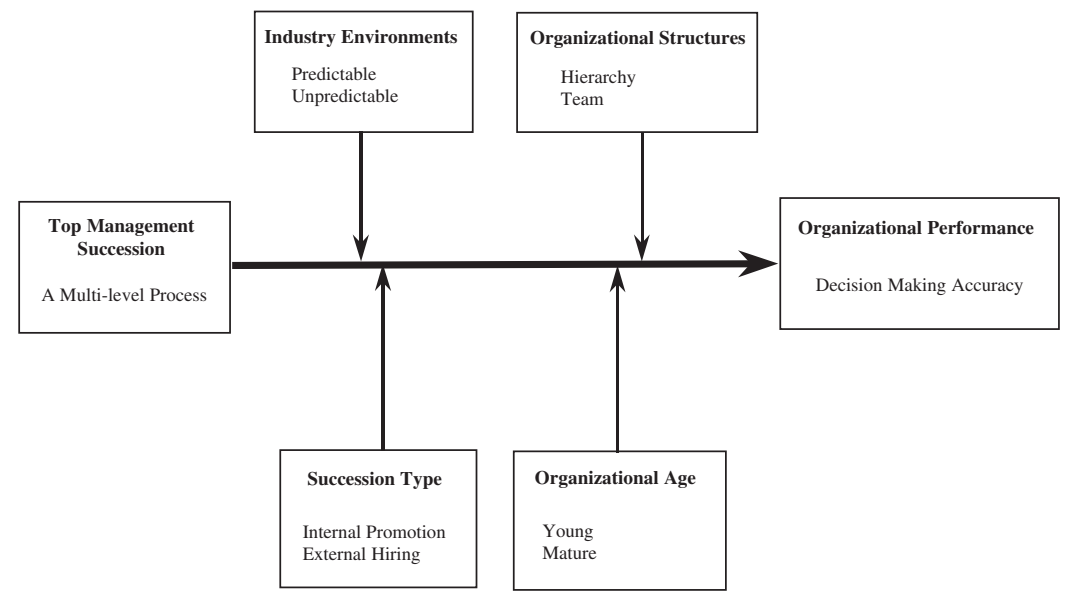

Figure 1: A Conceptual Framework of the Effect of Top Management Succession on Organizational Performance

approach and an appropriate methodology (House et al., 1995; Rousseau \& House, 1994).

\section{A MULTILEVEL APPROACH}

According to House et al. (1995), a multilevel approach or a "meso" approach

concerns the simultaneous study of at least two levels of analysis wherein (a) one or more levels concern individual or group behavioral processes or variables, (b) one or more levels concern organizational processes or variables, and (c) the processes by which the levels of analysis are related are articulated in the form of bridging, or linking, propositions. (p. 73)

A multilevel approach can allow researchers of organizations to investigate the fundamental building blocks of organizations, provide richer and more diverse interpretations of the meanings and functioning of organizations, and demonstrate deeper understanding of researchers' assumptions (Rousseau \& House, 1994). Therefore, it provides the best alternative to understanding top management successions, which involve multiple levels of linking processes in organizations. 
Scholars have also shown, however, that multilevel research requires fundamentally different thinking than conventional approaches (House et al., 1995; Klein et al., 1999; Rousseau \& House, 1994). From a multilevel perspective, the causal relationship between the micro-level behavior and the macro-level organizational outcome can go both ways and the interactions among different factors no longer follow statistical analogy.

\section{A COMPUTER MODELING TECHNIQUE}

To implement the multilevel approach and examine the various interacting factors, we have relied on the computer simulation method. Computer modeling, as "an extension of human cognition" (Simon, 1973) and "a third symbol language besides natural language and mathematics" (Ostrom, 1988), has its unique advantages over other methods such as qualitative case studies, quantitative data analyses, and mathematical modeling (Axelrod, 1997; Taber \& Timpone, 1996).

First of all, the problems we have attempted to address involve micromacro processes with complex and adaptive relations that are mathematically and statistically inexpressible and under environmental and organizational contexts that are impossible to manipulate in the real world (Axelrod, 1997; Earley \& Brittain, 1993; Harrison, 1998). Second, computer modeling can be used to express theory-to build models embedded in programs (Axelrod, 1997; Earley \& Brittain, 1993; Taber \& Timpone, 1996). It can also be used to enhance accuracy and realism of theories (Weick, 1979) by allowing the researchers to model the internal mechanisms of "black boxes" of organizations (Axelrod, 1997; Harrison, 1998) and move beyond loose conceptual terms in organization theories. Finally, computer modeling can provide a more systematic and powerful tool for potentially integrating different perspectives in organization and management studies (Pfeffer, 1993), which is also the hope of this study for the field of top management successions.

Since the seminal work by Cyert and March (1963), computational models have been effectively employed in numerous organizational studies (e.g., Carley and Lin, 1997; Earley \& Brittain, 1993; Harrison \& Carroll, 1991). Some scholars have also contrasted computational models with human experiments. For example, Carley and her associates (Carley, 1996a; Carley \& Lin, 1994; Carley, Prietula, \& Lin, 1998) have found that the outcome of their CORP (Computational Organizational Performance) model became very close to that of humans in laboratory experiments when limited experiential training was provided. Burton and Obel (1984) have further demonstrated that when compared with field experiments and laboratory experiments, 
computational models have performed well on all major dimensions: internal validity, statistical conclusion validity, external validity, and construct validity.

Like any other research method, computational modeling has its own limitations. We believe, however, by relying on this particular method, we will be able to systematically explore an important research issue, which would otherwise be impossible. We also hope that the results from this study will provide some new insights and directions for future research, both empirically and theoretically, which may greatly expand our thinking of the field of top management succession. The benefit of using computer modeling, therefore, far outweighs the opportunity loss if the current research is left in the segmented state.

\section{OVERVIEW OF THE MODEL}

Two main approaches to computational modeling have existed. The first one tends to follow the engineering tradition and assume that the reality can be fully captured if the model is complex enough (M. B. Thompson, 1994). They, however, have frequently ignored findings from the organization science and overlooked the underlying mechanism that truly drives the phenomena. For this study, we take a different approach, namely, an organization science-based approach. We follow the idea by Simon (1947) and recognize the limit of human cognition. Our model strives to focus on the essence of the reality that is most relevant to the research issue. This approach has been proven to be more beneficial for us to understand the underlying dynamics of the phenomenon. This is also a favored approach in the modeling discipline for achieving the balance of research purpose and model simplicity (Burton \& Obel, 1995).

Like many researchers of complex organizations, for this study, we adopt the agent-based method for our computational modeling as it has incorporated many developments in the field of artificial intelligence (Weiss, 1999). The agent-based simulation method allows the modeling of not only cognitively intelligent individual members (nodes) and their adaptive interpersonal relationships but also organizational-level outcomes in a dynamic and controlled setting (Axelrod, 1997). Agent-based models therefore permit researchers to examine the emergent patterns of human interactions based on more realistic replications of basic human behaviors (Carley \& Lin, 1997; Glance, Hogg, \& Huberman, 1997; Lounamaa \& March, 1987; Taber \& Timpone, 1996).

For this study, we built our model based on Carley and Lin's (1997) earlier version, which was also tested in their comparison studies with human 


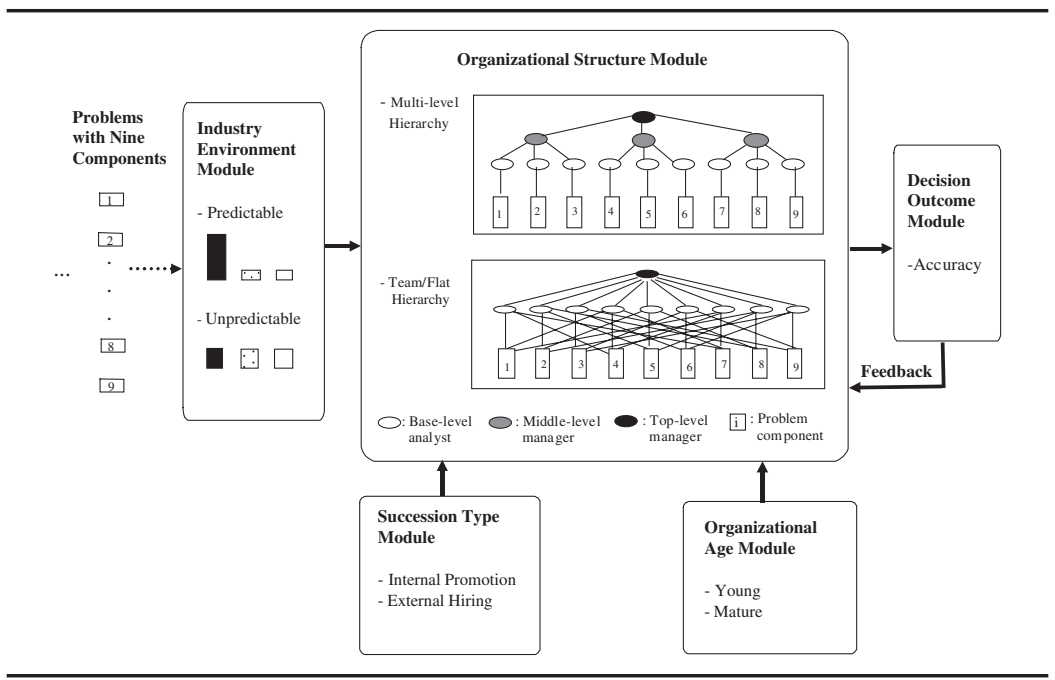

Figure 2: $\quad$ An Overview of the Computer Model

organizations (Carley, 1996a; Carley \& Lin, 1994; Carley et al., 1998). It has been proven to be both empirically valid and methodologically reliable. Our model, however, has extended their agent-based model in that it is interested in the role of a much broader set of contextual variables in the multilevel processes of a specific and important organizational phenomenon.

For this study, we have relied heavily on the literature in organizational learning, organization design, and the open systems perspective when making assumptions of the key components of the model (Carley, 1996b). Similar to the simulation work by Earley and Brittain (1993), our model is composed of multiple levels, specifically individual, organizational, and environmental. Our model has followed their approach and linked microlevel individual behavior to organizational-level performance with a dynamic process model that integrates individual learning, organizational design, knowledge transfer, and environmental uncertainty. The general computer simulation model is illustrated in Figure 2, with all the main modules to be further described below.

To run the computer model, the researcher can input parameters specifying the different choices of components based on the design of the simulation experiment. The model will then link the selected component modules to generate the corresponding performance results. The model's source code is written in $\mathrm{C}$ in a UNIX environment. Due to space limitations, not all 
technical details can be included here, although a general algorithm is listed in the appendix. Additional technical information can be obtained on request or from similar studies using agent-based modeling methods (Glance et al., 1997; Lin \& Carley, 1995; Lounamaa \& March, 1987; Weiss, 1999).

\section{MODELING THE INDIVIDUAL LEVEL: LEARNING AGENTS}

At the individual level of the computational model, the building blocks are "agents," which represent members of the organization. Similar to the work by Earley and Brittain (1993) and Lant and Hurley (1999), we assume that an individual agent is capable of learning from past experience, whether positive or negative (K. J. Cohen \& Cyert, 1965). Such a trial and error learning, according to Lant and Mezias (1992), is based on the assumption that "behavior that is associated with success will be repeated and behavior that is associated with failure will not be repeated." We create different agents in the computer program to allow them to have both memories and learning capabilities (Carley \& Lin, 1997; Glance et al., 1997). Each agent can carry out some basic functions such as reading information from other sources, processing information according to a specific procedure, passing out information, and learning from past experiences. Following the principle that prior knowledge can be represented in a person's cognitive structures to interpret new information signals (W. Cohen \& Levinthal, 1990), we have built, in our model, an experiential learning procedure for each agent to process the information and make his or her best possible judgment while relying on his or her past experiences (Carley \& Lin, 1997). For example, if an agent sees the following three pieces of information-1,2,3 (a subset of the nine components of the problem faced by the whole organization) - -he or she will trace back to the memory to see how these three pieces of information have led to what true decision outcomes for the whole organization in the past. If the frequencies of past true decisions being 1,2, and 3 with that partial set of information are 10,35 , and 4 , respectively, the member will report a decision of 2 , as this has occurred the most in the past.

Although such individuals are highly abstract, we believe they have captured the decision-making essence of a "boundedly-rational" human being (March \& Simon, 1958). Each individual follows the satisficing approach and is not keen on finding the best alternative. Rather, he or she is satisfied with the most convenient and most familiar solutions, which can be obtained through following existing organizational procedures or using heuristic shortcuts based on prior experience. We also assume that all individuals will eventually receive feedback about how the organization as a whole has 
performed (in the real world, such feedback can often be obtained through audit reports, shareholder reactions, and even the media), although such feedback may sometimes be misleading for specific individuals at the lower levels due to distributed decision-making setting and bounded rationality (Carley \& Lin, 1997; Lant \& Mezias, 1992). Our model therefore has also considered cases where learning may not always be beneficial, such as in many real world situations.

\section{MODELING THE ORGANIZATIONAL LEVEL: ORGANIZATIONAL STRUCTURES}

At the organizational level, similar to the work by Earley and Brittain (1993) and Carley and Lin (1997), we assume that each individual, although capable of learning and communicating, is also constrained by the design of the organizational settings such as communication structures. Scholars, in particular sociologists and organizational institutional theorists (Zucker, 1986; Coleman, 1990), have long argued that organizations can resort to structures and procedures to regulate their members' behaviors thus limiting individual discretion. Although there are different forms of organizational structures, organizations in the real world are mostly structured along the vertical and horizontal differentiation (Hall, 1991). As a result, we are limiting ourselves to the study of two extreme cases-hierarchy versus team structures (Figure 2) - because they are not only the most studied in management research but also represent the two ends of the structural spectrum (Weick, 1979). These two structures should pose different challenges to top management successions (Lin \& Hui, 1999). Similar modeling of organizational structures can be found in various other studies (Glance et al., 1997; Lin \& Hui, 1999).

Hierarchy. In this structure, there are nine bottom-level analysts (or baselevel units), three middle-level managers (or middle-level units), and one top-level manager. Each analyst examines one piece of information from the external industry environment and makes a recommendation to his or her immediate middle-level manager. Because each problem comprises nine individual characteristics, the information an analyst has access to is thus partially shared by other analysts. Each middle-level manager examines the recommendations from his or her subordinates and makes a recommendation to the top-level manager. The top-level manager examines the middle-level managers' recommendations and makes the organizational decision. There are two levels of management with the top-level manager as the top 
organizational level and the base-level analysts and middle-level managers as the subunit level.

Team (or flat hierarchy). In this structure, there are nine bottom-level analysts (or base-level units) and one top-level manager. Each analyst examines three pieces of information from the external industry environment and makes a recommendation. Each piece of information is accessed by three different analysts. All analysts report to the top-level manager. The manager examines these recommendations and makes the organizational decision. There is only one level of management with the top-level manager as the top organizational level and the base-level analysts as the subunit level. The manager of the team may also be considered a coordinator who bases his or her decisions on the collective opinions of all the team members.

The modeling of the two structures, although stylized, can allow us to examine, to a great extent, the impact of structural differences on top management successions.

\section{MODELING THE CROSS-LEVELS: TOP MANAGEMENT SUCCESSIONS}

Bridging both the individual and the organizational levels, we have modeled two types of top management successions based on the literature in this field (e.g., Guthrie \& Datta, 1997; Worrell et al., 1993): internal promotion and external hiring. This has allowed us to examine how different top management successions may affect organizational performance while being constrained by different organizational structure and later different environmental conditions. Although we understand that there can be other forms of top management succession under different conditions, we hope the results from the two main stylized succession types can bring a solid start to the more important and comprehensive issues in the future.

Internal promotion. In this type of top management succession, the toplevel manager is replaced by any of the immediate lower level members from within the same organization, whose position will be filled by a further lower level member in the organization or by a new recruit from outside of the organization. This treatment contains the assumption from the structural equivalence perspective and considers members at the same level to be equally competent (Lorrain \& White, 1971). This approach allows us to avoid some unnecessary biases in the selection process and eliminate some potential alternative explanations for the different effects by the two types of top 
management successions of interest: internal promotions versus external hirings. In another article (Phelan \& Lin, 2001), we have explored how different internal promotion mechanisms based on either competency, seniority, or other factors may affect organizational performance.

In this study, such successions through internal promotions are manifested in the computer model through the change of memories. If the organization is a three-tier hierarchy, for example, the successor will be from the middle level, whose memory of the past experience will now replace that of the top-level manager. Following that, a randomly chosen base-level member will be promoted to fill the middle-level member's position, again with the memory redistribution. An untrained new member will finally be recruited to fill the base-level member's position. If the organization is a twotier team, the successor will be randomly chosen from the base level with the new opening at the base level being filled by a new recruit.

External hiring. In this type of top management succession, the top-level manager of an organization is replaced by a top-level manager of another organization of similar structure while operating in a different environment. Such a succession is again manifested in the computer model through the replacement of agent memories. This, too, is an abstracted modeling part, although we believe it can help us achieve the research goal of the study. In future studies, we may further explore external hirings from organizations of different structures.

\section{MODELING THE ENVIRONMENTAL LEVEL: PREDICTABILITY AND UNPREDICTABILITY}

At the environmental level, following the work by J. D. Thompson (1967), we assume that organizations are open systems so that they can be affected by the uncertainty of the environment. Scholars have long listed various environmental characteristics that can affect an organization (Hannan \& Freeman, 1977). Among them, the uncertainty of the environment has received the most attention and is considered the most critical of all (Aldrich, 1979; Virany et al., 1992). We model environmental uncertainty based on the work of Aldrich (1979) that focuses on the distribution of the nature of different task problems. The use of a computer simulation method has also allowed us to prespecify the true nature of each problem faced by the organization, thus permitting us to examine the impact of environment of different natures.

In the computer simulation model, a ternary choice classification task has been built for organizations to make decisions regarding a series of quasirepetitive problems, relying on multiple indicators that can only be partly 
accessed by different organizational members in a distributed environment (Carley \& Lin, 1997). The basic component of such a problem-solving model has been implemented in a variety of studies including the one by Hollenbeck et al. (1998). In this study, we have further expanded it to include a much richer organizational and environmental context. This task can find resemblance in real world settings that involve distributed decision making. For example, in a manufacturing planning setting, the task can be considered as consisting of a series of production proposals that require the organization to decide whether to produce, hold, or reject the production of certain products based on information from nine indicators such as financial status of the company, human resources, technology, customer preference, and so forth. Because of bounded rationality, each member of the organization naturally can only process a limited number of pieces of information although each one or two single indicators may not provide a complete picture of the situation. Thus, an organization's decision requires coordination among various people who work with different indicators.

Organizations operate under environments that can be predictable or unpredictable (Aldrich, 1979). Organizations retrieve information from the environment and make judgments to respond to the environment. The nature of the industry environment and the way in which organizations respond to the environment may affect organizations' outcomes. In this study, we follow the work by Aldrich (1979) and predefine two types of environment to allow different distributions of problems of various natures to reflect the predictability/unpredictability of the environment. Studies have also found that to model the predictability/unpredictability of the environment, the relationships of the components in the equation may not be that important as long as the distribution captures whether the environment is dispersed with all different types of problems or is concentrated with few types of problems (Carley \& Lin, 1997). The detailed formula is as follows:

$$
\Sigma=\mathrm{T} 1+\mathrm{T} 2+\mathrm{T} 3+\mathrm{T} 4+\mathrm{T} 5+\mathrm{T} 6+\mathrm{T} 7+\mathrm{T} 8+\mathrm{T} 9
$$

In the formula, each $\mathrm{T}$ refers to one specific indicator that can take an integer value ranging from 1 to 3 , with a bigger number representing a more positive indication toward the decision to produce. By varying all possible values of nine indicators, the computer model can create an industry environment that has a total of 19,683 different combinations of problems. To make the model more concrete, the task of the model can be to determine whether a particular product has the potential to contribute to the overall growth of the company. Each product has nine attributes that are manipulated by the 
computer program. These nine attributes can be interpreted as factors that include the strategic match with company, growth rate, total investment, cash flow, available technology, available manpower, customer preference, competition, and profitability. For the predictable industry environment we define the true state of the problem in such a way that if $\Sigma \leq 13$ then the true decision should be to reject; if $\Sigma \geq 18$, then the correct decision should be to produce, and if other values then the true decision should be to hold. Following this formula, the industry environment contains 625 problems whose true decision should be to reject (meaning not pursue), 7,647 problems whose true decisions should be to hold (wait before pursuing), and 11,411 problems whose true decisions should be to produce. With the domination of one type of problems whose true state is to produce, the organization is facing a more certain environment and may have less of a chance of making a mistake if it decides to produce.

For the unpredictable industry environment, we use the same formula, but we define the true decision as reject if $\Sigma \leq 16$, as produce if $\Sigma \geq 20$, and as hold if otherwise. With this manipulation, we have an industry environment that regards one third of decisions of reject as correct, one third of decisions of hold as correct, and one third of decisions of produce as correct. In this case, the organization may have a tougher time making the correct decisions when faced with a particular problem because of increased uncertainty.

The manipulations of the industry environment are modeled independently and are not known to organizations. Because of such manipulations, we will then be able to examine whether such industry environment manipulation has an effect on organizations with different top management successions.

\section{MODELING OTHER ORGANIZATIONAL CHARACTERISTICS: ORGANIZATIONAL AGE}

For this study, we also wish to examine if organizational age may be a moderating factor for top management successions. Organizational age is fundamentally about the accumulated experience of an organization, the importance of which has been frequently documented in prior studies (Carroll \& Harrison, 1998; Hannan \& Freeman, 1984; Glance et al., 1997; Lin \& Hui, 1999). For this study, we focus on two extreme cases of organizational age: young or mature. As organizational age is about the learning experience from past problems, we use the number of problems processed by an organization as an indicator for age. In this sense, each problem can also be considered an event that requires time to process. To differentiate young from mature organizations, we purposely let young organizations process 
much fewer problems than mature organizations before successions take place. Our preliminary test shows that the experience of an organization can be significantly different if it has processed less than 30 problems as compared with more than 300 problems. Prior experiments using human participants for decision-making tasks have also shown that it takes about 30 problems for a human being to be gaining sufficient experience to start to make educated judgment (Carley, 1996a; Carley \& Lin, 1994; Carley et al., 1998). The performance of a simulated organization in the model becomes stable once it has processed 300 problems. Therefore to define a young organization, we allow the organization to process 20 problems, and for a mature organization we allow the organization to process 1,000 problems, before successions are to take place. As will be described later, this will also give us enough room to examine the performance difference before and after successions.

\section{MODELING THE ORGANIZATIONAL-LEVEL OUTCOME: DECISION-MAKING PERFORMANCE}

For this study, we focus on the decision-making accuracy of the organization as an indicator of organizational performance. Specifically, the performance is measured as the percentage of correct decisions made by the organization given the number of problems processed by the organization under the prespecified experimental conditions. Therefore, to study the effect of top management succession on organizational performance, we can examine the difference between the performance after the succession and the performance prior to the succession (Pfeffer \& Davis-Blake, 1986).

\section{VIRTUAL EXPERIMENTS}

With the above modeling designs, we can have a series of 16 virtual experiments based on four factors, each with two possible values: 2 types of top management succession $(1=$ internal promotion or $0=$ external hiring $) \times$ 2 types of organizational structure $(1=$ hierarchy or $0=$ team $) \times 2$ types of organizational age $(1=$ mature or $0=$ young $) \times 2$ type of industry environment $(1=$ predictable or $0=$ unpredictable). For each of the 16 experiments, we provide the organization with a set of problems generated from the current industry environment. We then measure the organization's performance at different stages of the problem periods before and after the succession depending on the type of organizational age.

As we can see, for each factor of the experimental design, we have focused on the opposite extremes through the purposeful selection of certain 
parameter values in the model design. Doing so has allowed us to effectively pursue our research issue, that is, to examine the differential effect of the organizational and environmental context on top management successions. This is also similar to a "what-if" analysis of the research issue. The actual numbers in creating these extreme opposites therefore becomes less important than the fact that there are significant differences between them.

To run the virtual simulation experiments, a researcher can specify the particular type of industry environment, organizational structure, succession type, and organizational age he or she is interested in. Once the parameters are inputted into the computer model, the computer will conduct top management succession under these conditions to see how performance is affected. Specifically, each organization will go through either 20 or 1,000 random problems from the studied industry environment, depending on organizational age, before the top management succession. After that the organization will go through another 1,000 random problems from the same industry environment. The performance by the organization right before (last 10 problems leading to top management succession) and after the top management succession (the first 10 problems after the top management succession) is then recorded.

\section{RESULTS}

The descriptive statistics and the correlation are listed in Table 1, along with the definition and possible values of each variable. The negative mean value of RELPERF shows that on average, top management successions may not help organizational performance, which seems to echo the vicious circle view of top management successions (Friedman \& Singh, 1989).

Following the open system's perspective, we extend our exploration into the broad organizational and environmental contexts. We rely on a regression analysis and look at how the four variables, ENVIRONMNT, STRU, STYPE, and MATURITY, plus the interaction of ENVIRONMNT and STRU, contribute to the performance change RELPERF resulted from top management successions. Table 2 contains two models: Model 1, which tests the main effect of the four variables and Model 2, which also contains the interactions between ENVIRONMNT and STRU (Table 2). To test Hypotheses 1,2, 4, and 5, we rely mainly on Model 1 . To test Hypothesis 3, we rely on Model 2. 
TABLE 1

Descriptive Statistics and Correlation

\begin{tabular}{|c|c|c|c|c|c|c|c|c|c|}
\hline & $\mathrm{N}$ & Minimum & Maximum & M & $\mathrm{SD}$ & 1 & 2 & 3 & 4 \\
\hline 1. RPERF & 480 & -71.82 & 53.64 & -5.02 & 22.13 & & & & \\
\hline 2. ENVIRONMNT & 480 & .00 & 1.00 & .50 & .50 & $-.108^{*}$ & & & \\
\hline 3. STRU & 480 & .00 & 1.00 & .50 & .50 & .030 & .000 & & \\
\hline 4. STYPE & 480 & .00 & 1.00 & .50 & .50 & $.245^{* *}$ & .000 & .000 & \\
\hline 5. MATURITY & 480 & .00 & 1.00 & .50 & .50 & $-.193 * *$ & .000 & .000 & .000 \\
\hline
\end{tabular}

NOTE: RPERF: Relative organizational performance due to succession, a value ranging from -100 to 100; ENVIRONMNT: Industry environment, with 1 for predictable and 0 for unpredictable environment; STRU: Organizational structure, with 1 for hierarchy and 0 for team structure; STYPE: Succession type, with 1 for internal promotion and 0 for external hiring; MATURITY: Maturity of organization, with 1 for mature and 0 for young organizations.

*Correlation is significant at the .05 level (2-tailed). ** Correlation is significant at the .01 level (2-tailed).

TABLE 2

Regression Results on the Change of Performance (RELPERF) Due to Top Management Successions

\begin{tabular}{lcc}
\hline \hline Variables & $\begin{array}{c}\text { Model 1 } \\
\text { Coefficients }\end{array}$ & $\begin{array}{c}\text { Model 2 } \\
\text { Coefficients }\end{array}$ \\
\hline Intercept & $-4.446^{*}$ & -.807 \\
ENVIRONMNT & $-4.755^{*}$ & $-12.033^{* * *}$ \\
STRU & 1.314 & $-5.964^{*}$ \\
STYPE & $10.814^{* * *}$ & $10.814^{* * *}$ \\
MATURITY & $-8.529^{* * *}$ & $-8.529 * * *$ \\
ENVIRONMNT $\times$ STRU & - & $14.556^{* * *}$ \\
$N$ 480 & 480 & .127 \\
$R^{2}$ (adjusted) & .102 & .000 \\
$P$ (model) & .000 & \\
\hline
\end{tabular}

$* p<.05 . * * * p<.005$.

\section{HYPOTHESIS 1: THE ROLE OF INDUSTRY ENVIRONMENT}

When we look at the effect of ENVIRONMNT while controlling for other factors in Model 1, we can see that it is significant, although not at the strongest level. The result shows that when compared with an unpredictable environment, a predictable environment tends to negatively affect the change of 
organizational performance after top management successions. This supports Hypothesis 1 . This result suggests that in a stable and routine environment, established institutional practices may provide continuity of valuable knowledge to organizations whereas changes at the top management level may disrupt such continuities.

\section{HYPOTHESIS 2: THE ROLE OF ORGANIZATIONAL STRUCTURE}

When examining the effect of different forms of organizations in Model 1, we can see that the coefficient of STRU is not statistically significant. In other words, organizational structure has shown little effect on top management succession. This result is interesting in that it suggests that the trade-off of having a hierarchy versus a team structure may not be that big to offset the effect of top management successions. This supports Hypothesis 2.

\section{HYPOTHESIS 4: THE ROLE OF SUCCESSION TYPE}

From Model 1, we can see a significant and positive effect by STYPE on the change of organizational performance due to top management successions. In another words, internal promotions tend to help organizations to achieve better performance than external hirings. This suggests that external hirings may pose more challenges to organizations in the short term. This also seems to echo the view that external hiring is often used for public relations reasons instead of for performance purposes (Lieberson \& O'Connor, 1972; Ocasio, 1994). The result supports Hypothesis 4.

\section{HYPOTHESIS 5: THE ROLE OF ORGANIZATIONAL AGE}

When examining, in Model 1, the effect of maturity of organizations on the change of organizational performance due to top management successions, we can see a significant and negative effect by MATURITY. This result shows that top management succession is generally not as helpful for mature organizations as for young organizations. This is consistent with the views by some scholars who argue that mature organizations can have a more institutionalized environment and a stronger structural inertia, which may reduce the role of individual top managers (Hannan \& Freeman, 1984; Powell \& DiMaggio, 1991). This supports Hypothesis 5.

\section{HYPOTHESIS 3: THE ROLE OF THE INTERACTION BETWEEN ENVIRONMENT AND ORGANIZATIONAL STRUCTURE}

Now we look at Model 2 with the interactions of industry environment and organizational structure. We can see that the interaction has a strong and sig- 
nificantly positive effect on the change of organizational performance. This result shows that in a predictable industry environment, a hierarchy structure can help top management succession to have a positive impact on organizational performance. In contrast, in an unpredictable industry environment, a team structure may provide the help for top management succession. These results suggest that whereas industry environment can have impact on top management succession, organizations can also design different structures to counter environmental challenges (Courtright et al., 1989; J. D. Thompson, 1967). Hypothesis 3 is thus supported.

\section{SUMMARY}

The results from the simulation model have provided support for all five of the hypotheses. They have also pointed out the conditions under which top management successions may be helpful to organizational performance. When we compare the main effects of the four variables in Model 2 with those in Model 1, we can see a similar pattern, with the exception of STRU, which now has a slightly significant coefficient. This again suggests that the value of an organizational structure may be contingent on the nature of the environment an organization is in.

\section{DISCUSSION}

From an open system's perspective, this study has examined the effect of top management successions on organizational performance, in particular, decision-making accuracy, while considering various important contingency factors such as industry environment, organizational structure, succession type, and organizational age. Through a formal computer model, we have explored both the internal processes of top management successions in decision-making settings and the interactions between such processes and the various contingency factors. The results show that whether top management successions may affect organizational performance and, if so, how organizational performance is affected, depends on the contextual variables. Our study suggests that an open system's perspective powered by a systematic and sophisticated approach may yield more concrete insights into the issue, thus bridging different views in the field of top management successions.

\section{MAIN CONTRIBUTIONS OF THE STUDY}

The current study differs from prior research of top management succession in four main aspects: an open systems perspective with internal and 
external organizational factors, a focus on organizational outcome (decisionmaking accuracy), a multilevel approach, and a computational methodology. First, we have taken the open system's perspective and considered organizations as affected by the larger context of their environments (Aldrich, 1979; Scott, 1987; J. D. Thompson, 1967). Organizations must respond to the environmental challenges to survive. Furthermore, the effectiveness of a particular organization may have to be evaluated ultimately against the external constituencies of an organization (Aoki, 1994). Organizational environments provide organizations with opportunities and constraints. Thus, the functionality of a particular organizational activity, such as top management succession, can and needs to be examined in terms of its performance under organizational environments with which the organization continuously interacts (Lawrence \& Lorsch, 1967; Scott, 1987; J. D. Thompson, 1967).

Second, our study has focused on an objective outcome of organizations, namely, the accuracy of decision making. We take the view that poor decision making causes poor organizational performance, which is also one of the main causes for top management change (Pfeffer \& Davis-Blake, 1986). In turn, the outcome of top management successions affects how organizations make future decisions. Whereas many prior studies have focused on such outcomes as stock price and stockholder reactions (Worrell et al., 1993), we take the position that decision making is the key to any organizational operation and that organizations must make good decisions to survive (Scott, 1987). Decision-making accuracy is one of the most important performance measures of organizations as it is often regarded as the heart of an organization (Simon, 1947), and organizational operation is often represented as a series of decision-making activities (Scott, 1987).

Third, we have taken a multilevel approach to address the top management succession issue. According to Rousseau and House (1994), such a multilevel approach can allow researchers to investigate the fundamental building blocks of organizations, provide richer and more diverse interpretations of the meanings and functioning of organizations, and demonstrate deeper understanding of the researchers' assumptions. We believe such an approach also provides the best alternative to understand how top management succession affects organizations. With this multilevel approach coupled with a sophisticated modeling technique, we have also moved beyond the conventional contingency theory by providing systematic, concrete, and precise insights (Schoonhoven, 1981). Multilevel research also requires nonconventional thinking when we intend to interpret the causal relationships or interaction effects. Oftentimes, the interactions among different factors no longer follow statistical analogy (House et al., 1995). These, 
however, may also pose bigger challenges for multilevel researchers to reach the general management audience.

Finally, we have adopted a computational methodology. Studies in top management succession often rely on archival data or field methodologies. These methodologies have their merits, but no methodology itself can offer a complete picture for the complex real world phenomena under study. For example, archival data rarely capture intraorganizational practices. Field studies, however, would have to address the issue of how to enhance the response rate from participants (e.g., Jobber, Mirza, \& Wee, 1991). Studies on top management succession may benefit from methodologies besides the use of archival data and field surveys. In the present study, we have relied on a different methodology - computer modeling. Computer modeling has the advantage of manipulating even complex environmental settings and affording higher levels of control, which are impossible to accomplish in the real world. Thus, computer modeling can complement results obtained via archival data or field studies and further advance theoretical thoughts by providing a comprehensive and internally coherent model. Scholars such as Axelrod (1997) have even claimed that "simulation is necessary because the interactions of adaptive agents typically lead to nonlinear effects that are not amenable to the deductive tools of formal mathematics" (p. 4). He further argues that "the simulation of an agent-based model is often the only viable way to study populations of agents who are adaptive rather than fully rational" (p. 4). Harrison (1998) also states that "simulation is similar to theoretical derivation in a very fundamental way. Both approaches obtain results from a set of assumptions. The results are the logical and inevitable consequences of the assumptions, barring errors."

\section{VALIDITY ISSUES OF THE STUDY}

Like any other simulation studies, this study needs to confront the issue of validity, which is related to the grounding of the assumptions of the model. Grounding involves establishing the reasonableness of a computational model, specifically, demonstrating that the simplifications made in designing the model do not seriously detract from its credibility and the likelihood that it will provide important insights (Carley, 1996b). Some scholars even argue that "simulation can also be a valuable research tool even when grounding is not possible" as "it is still a legitimate scientific endeavor" (Harrison, 1998).

In the process of building the model, we have relied heavily on prior research in organizational learning, organization design, and the open system's perspective. We believe our model has captured features that are 
central to the organization, although it may not perfectly fit the description of any one real world organization. The building blocks of our model are boundedly rational individuals who are capable of learning and communicating while under constrained organizational and environmental conditions (March \& Simon, 1958; Simon, 1947). Even though the building blocks are relatively simple, studies have shown that the outcome at the organizational level can be complex or even chaotic, given the fact that the organizations in our model consist of dynamic and nonlinear relationships (Earley \& Brittain, 1993).

Similar to the work of Earley and Brittain (1993), we do not intend our model to be all encompassing. Instead, we want to have a balanced model by choosing a specific set of variables to capture particular aspects of top management succession and organizational performance (Burton \& Obel, 1995). This philosophy of model can also be seen in the work of K. J. Cohen and Cyert (1965). We also understand that although there are advantages to using the simulation method, results from a simulation model are only a precursor for future empirical research (Earley \& Brittain, 1993).

The validity of our model can be further enhanced by the fact that the core of the simulation model is based on prior models that have been empirically tested (e.g., Carley, 1996a). Based on the studies by Carley and her associates (Carley, 1996a; Carley et al., 1998), such models can very well capture the basic behaviors of human decision making, in particular when the tasks are relatively simple and the settings are controlled.

This study has its boundary conditions and limitations. For example, it has only focused on natural top management successions and the consequences of such successions. Performance antecedents are not emphasized, although considered, in the demonstration of relative succession effects. Additionally, this study has only examined decision making in a distributed setting. There are situations that we have not included, in which organizations can face more homogeneous tasks or simpler tasks that do not require the distributed expertise and so consensus decision making may be more desirable. In future studies, we should also explore a wide range of characteristics of the industry environment to fully understand the environmental conditions of top management succession. With these boundary conditions, we should exercise caution when attempting to apply the conclusions of this study to a broader setting.

This study has also taken a strong structural equivalence view in that it regards individuals in structurally equivalent roles as having similar capabilities and functions, although their relationships can change (Lorrain \& White, 1971). This view is different from some of the micropsychological 
perspectives. Although we wish we could have developed a model that captures all individual differences, we also understand that would be impossible to do at the current stage without the contamination of the more important behavioral effects this study is focusing on. By taking the structural equivalence approach, we have been able to derive the effect of top management succession as a result of behaviors in well-controlled environmental and organizational contexts.

\section{FUTURE DIRECTIONS}

With the further development of the field of top management succession research and the advancement of modeling technology, this study can be improved to encompass broader aspects of top management successions with different cultural implications, while considering wider ranges of environmental and organizational context, which may ultimately yield further insights. It will also be beneficial for us to learn more from available cases of real world organizations, which, although they may not be as systematic and controlled, may help provide new empirical information for further theoretical development of the model. Despite these areas for potential improvement, we believe findings from this study can shed light on the field of top management succession research and provide new directions that can be further pursued both theoretically and empirically.

\section{APPENDIX A GENERAL ALGORITHM OF THE COMPUTER MODEL}

\section{Experimental Setting}

1. Set experimental context through the selection of industry environment (predictable or unpredictable), organizational structure (hierarchy or team), promotion type (internal promotion or external hiring), and organizational age (mature or young).

2. If all possible combinations have been selected, go to Step 13; otherwise, go to Step 3.

\section{Problem Generation}

3. Generate random task problems, each having nine components that can randomly be 1,2, or 3 for the organization to process under the selected experimental setting. 


\section{Organizational Processes}

4. Each bottom-level analyst accesses a subset of the nine problem components as specified by the organization structure, makes a decision using the experiential learning procedure, and passes up the recommendation to his or her designated manager.

5. If the organization structure is a team/flat hierarchy structure, skip this step and go to Step 6. Each middle-level manager reads recommendations from his or her subordinates as specified by the organization structure, makes a decision using the experiential learning procedure and passes up the recommendation to the top-level manager.

6. The top-level manager reads recommendations from his or her subordinates as specified by the organizational structure and makes the final decision using the experiential learning procedure.

7. The computer registers the top-level manager's final decision as the organization's decision and calculates the true nature of the problem based on the formula from the specified task environment. The computer then compares the organizational decision with the true nature of the problem, records the comparison results, and provides feedback to the whole organization.

8. If the pre-specified number of problems have been processed, go to Step 9; otherwise, go to Step 3.

\section{Top Management Successions}

9. If the organizational age is mature, succession sequence happens after 1,000 problems have been processed by the organization; if the organizational age is young, succession sequence happens after only 20 problems have been processed by the organization.

10. If the succession type is internal promotion, succession sequence goes through the specified internal promotion chain reactions and memory replacements; if the succession type is external hiring, succession sequence allows the replacement of the top-level manager's memory by another one from outside the organization across a different industry environment.

11. Go through Steps 3-7 again after the succession.

12. If the prespecified number of problems have been processed, go to Step 1; otherwise, go to Step 11.

13. Calculate and compare organizations' decision performance prior to and after successions under each experimental setting.

\section{REFERENCES}

Aldrich, H. E. (1979). Organizations and environment. Englewood Cliffs, NJ: Prentice Hall.

Aoki, M. (1994). The contingent governance of teams: Analysis of institutional complementarity. International Economic Review, 35(3), 657-676. 
Axelrod, R. (1997). The complexity of cooperation: Agent-based models of competition and collaboration. Princeton, NJ: Princeton University Press.

Beatty, R. P., \& Zajac, E. J. (1987). CEO change and firm performance in large corporations: Succession effects and manager effects. Strategic Management Journal, 8(4), 305-317.

Boeker, W. (1992). Power and managerial dismissal: Scapegoating at the top. Administrative Science Quarterly, 37(3), 400-421.

Burns, T., \& Stalker, G. M. (1961). The management of innovation. London: Tavistock Limited.

Burton, R. M., \& Obel, B. (1984). Designing efficient organizations: Modeling and experimentation. Amsterdam, the Netherlands: Elsevier Science.

Burton, R. M., \& Obel, B. (1995). The validity of computational models in organization science: From model realism to purpose of the model. Computational and Mathematical Organization Theory, 1(1), 57-71.

Cameron, K. S. (1986). Effectiveness as paradox: consensus and conflict in conceptions of organizational effectiveness. Management Science, 32(5), 539-553.

Cannella, A. A., Jr., \& Lubatkin, M. (1993). Succession as a sociological process: Internal impediments to outsider selection. Academy of Management Journal, 36(4), 763-793.

Carley, K. M. (1996a). A comparison of artificial and human organizations. Journal of Economic Behavior and Organizations, 31(2), 175-191.

Carley, K. M. (1996b). Validating computational models (Working paper). Pittsburgh, PA: Carnegie Mellon University.

Carley, K. M., \& Lin, Z. (1994, August). Organizational shifts: Combining computational modeling and empirical analysis. Sociological abstract presented at the 89th Annual Meeting of the American Sociological Association, Los Angeles, CA.

Carley, K. M., \& Lin, Z. (1997). A theoretical study of organizational performance under information distortion. Management Science, 43(7), 976-997.

Carley, K. M., Prietula, M., \& Lin, Z. (1998). Design versus cognition: The interaction of agent cognition and organizational design on organizational performance. Journal of Artificial Societies and Social Simulation, 1(3), 1-19.

Carroll, G. R. (1984). Dynamics of publisher succession in newspaper organizations. Administrative Science Quarterly, 29, 93-113.

Carroll, G. R., \& Harrison, J. R. (1998). Organizational demography and culture: Insights from a formal model and simulation. Administrative Science Quarterly, 43(3), 637-667.

Child, J. (1972). Organizational structure, environment, and performance: The role of strategic choice. Sociology, 6, 1-22.

Cohen, K. J., \& Cyert, R. M. (1965). Simulation of organizational behavior. In J. G. March (Ed.), Handbook in organizations (pp. 305-334). Chicago: Rand McNally.

Cohen, W., \& Levinthal, D. (1990). Absorptive capacity: A new perspective on learning and innovation. Administrative Science Quarterly, 35(1), 128-152.

Cohen, M. D., March, J. G., \& Olsen, J. P. (1972). A garbage can model of organizational choice. Administrative Science Quarterly, 17(1), 1-25.

Coleman, J. S. (1990). Foundations of social theory. Cambridge, MA: Harvard University Press.

Courtright, J. A., Fairhurst, G. T., \& Rogers, L. E. (1989). Interaction patterns in organic and mechanistic systems. Academy of Management Journal, 32(4), 773-802.

Cyert, R. M., \& March, J. G. (1963). A behavioral theory of the firm. Englewood Cliffs, NJ: Prentice Hall.

Dalton, D. R., \& Kesner, I. F. (1985). Organizational performance as an antecedent of inside/outside chief executive succession: An empirical assessment. Academy of Management Journal, 28(4), 749-762. 
Datta, D. K., \& Guthrie, J. P. (1994). Executive succession: Organizational antecedents of CEO characteristics. Strategic Management Journal, 15(7), 569-577.

Datta, D. K., \& Rajagopalan, N. (1998). Industry structure and CEO characteristics: An empirical study of succession events. Strategic Management Journal, 19(9), 833-852.

Davidson, W. N., III, Worrell, D. L., \& Dutia, D. (1993). The stock market effects of CEO succession in bankrupt firms. Journal of Management, 19(3), 517-533.

Day, D. V., \& Lord, R. G. (1988). Executive leadership and organizational performance: Suggestions for a new theory and methodology. Journal of Management, 14(3), 453-464.

Earley, P. C., \& Brittain, J. (1993). Cross-level analysis of organizations: Social resource management model. In B. M. Staw \& L. L. Cummings (Eds.), Research in organizational behavior (Vol. 5, pp. 357-408). Greenwich, CT: JAI.

Friedman, S. D., \& Singh, H. (1989). CEO succession and stockholder reaction: The influence of organizational context and event content. Academy of Management Journal, 32(4), 718-744.

Gamson, W. A., \& Scotch, N. A. (1964). Scapegoating in baseball. American Journal of Sociology, 70, 69-72.

Gifford, D., Jr. (1997). CEO turnover: The importance of symbolism. Harvard Business Review, 75(1), 9-10.

Glance, N. S., Hogg, T., \& Huberman, B. A. (1997). Training and turnover in the evolution of organizations. Organization Science, 8(1), 84-96.

Goodstein, J., \& Boeker, W. (1991). Turbulence at the top: A new perspective on governance structure changes and strategic change. Academy of Management Journal, 34(2), 306-330.

Greiner, L. E., \& Bhambri, A. (1989). New CEO intervention and dynamics of deliberate strategic change. Strategic Management Journal, 10, 67-86.

Grusky, O. (1963). Managerial succession and organizational effectiveness. American Journal of Sociology, 69, 21-31.

Guest, R. (1962). Managerial succession in complex organizations. American Journal of Sociology, 68, 47-64.

Guthrie, J. P., \& Datta, D. K. (1997). Contextual influences on executive selection: Firm characteristics and CEO experience. Journal of Management Studies, 34(4), 537-560.

Guthrie, J. P., \& Olian, J. D. (1991). Does context affect staffing? The case of general managers. Personnel Psychology, 44, 263-292.

Hall, R. H. (1991). Organizations: Structures, processes, and outcomes (5th ed.). Englewood Cliffs, NJ: Prentice Hall.

Hambrick, D. C., \& Mason, P. A. (1984). Upper echelons: The organization as a reflection of its top managers. Academy of Management Review, 9, 193-206.

Hannan, M. T., \& Freeman, J. (1977). The population ecology of organizations. American Journal of Sociology, 82, 929-964.

Hannan, M. T., \& Freeman, J. (1984). Structural inertia and organizational change. American Sociological Review, 49, 149-164.

Hannan, M. T., \& Freeman, J. (1989). Organizational ecology. Cambridge, MA: Harvard University Press.

Harrison, J. R. (1998, September). The concept of simulation in organizational research. Paper presented at the SCANCOR Conference, Samples of the future, Stanford University, CA.

Harrison, J. R., \& Carroll, G. R. (1991). Keeping the faith: A model of cultural transmission in formal organizations. Administrative Science Quarterly, 36(4), 552-582.

Haveman, H. A. (1993). Ghosts of managers past: Managerial succession and organizational mortality. Academy of Management Journal, 36(4), 864-881.

Helmich, D. L. (1974). Organizational growth and succession patterns. Academy of Management Journal, 17, 771-775. 
Helmich, D. L., \& Brown, W. B. (1972). Successor type and organizational change in the corporate enterprise. Administrative Science Quarterly, 17, 371-381.

Hollenbeck, J. R., Ilgen, D. R., LePine, J. A., Colquitt, J. A., \& Hedlund, J. (1998). Extending the multilevel theory of team decision making: Effects of feedback and experience in hierarchical teams. Academy of Management Journal, 41(3), 269-282.

House, R., Rousseau, D. M., \& Thomas-Hunt, M. (1995). The meso paradigm: A framework for the integration of micro and macro organizational behavior. In L. L. Cummings, \& B. M. Staw (Eds.), Research in organizational behavior (Vol. 17, pp. 71-114). Greenwich, CT: JAI.

Janis, I. (1982). Victims of groupthink: A psychological study of foreign policy decisions and fiascos (2nd ed.). Boston: Houghton Mifflin.

Jobber, D., Mirza, H., \& Wee, K. H. (1991). Incentives and response rates to cross-national business. Journal of International Business Studies, 22(4), 711-721.

Kahn, R. L. (1977). Organizational effectiveness: An overview. In P. S. Goodman \& J. M. Pennings (Eds.), New perspectives on organizational effectiveness. San Francisco: JosseyBass.

Kesner, I. F. \& Dalton, D. R. (1994). Top management turnover and CEO succession: An investigation of the effects of turnover on performance. Journal of Management Studies, 31(5), 701-713.

Kesner, I. F., \& Sebora, T. C. (1994). Executive succession: Past, present and future. Journal of Management, 20, 327-372.

Kimberly, J. R., \& Miles, R. H. (1980). The organizational life cycle. San Francisco: JosseyBass.

Klein, K. J., Tosi, H., \& Cannella, A. A., Jr. (1999). Multilevel theory building: Benefits, barriers, and new developments. Academy of Management Review, 24(2), 243-248.

Lant, T. K. \& Hurley, A. E. (1999). A contingency model of response to performance feedback. Group and Organization Management, 24(4), 421-437.

Lant, T. K., \& Mezias, S. J. (1992). An organizational learning model of convergence and reorientation. Organization Science, 3, 47-71.

Lawrence, P. R., \& Lorsch, J. W. (1967). Organization and environment: Managing differentiation and integration. Boston: Harvard University, Graduate School of Business Administration.

Lieberson, S., \& O'Connor, J. F. (1972). Leadership and organizational performance: A study of large corporations. American Sociological Review, 37, 117-130.

Lin, Z., \& Carley, K. M. (1995). DYCORP: A computational framework for examining organizational performance under dynamic conditions. Journal of Mathematical Sociology, 20d(2/ 3), 193-217.

Lin, Z., \& Carley, K. M. (1997a). Organizational decision making and error in a dynamic task environment. Journal of Mathematical Sociology, 22(2), 125-150.

Lin, Z., \& Carley, K. M. (1997b). Organizational response: The cost performance tradeoff. Management Science, 43(2), 217-234.

Lin, Z., \& Hui, C. (1999). Should lean replace mass organization systems: A theoretical examination from a management coordination perspective. Journal of International Business Studies, 30(1), 45-80.

Lorrain, F., \& White, H. C. (1971). Structural equivalence of individuals in social networks. Journal of Mathematical Sociology, 1, 49-80.

Lounamaa, P. H. \& March, J. G. (1987). Adaptive coordination of a learning team. Management Science, 33(1), 107-123.

Mackenzie, K. D. (1978). Organizational strucutures. Arlington Heights, IL: AHM. 


\section{GROUP \& ORGANIZATION MANAGEMENT}

March, J. G., \& Simon, H. A. (1958). Organizations. New York: John Wiley.

Miller, D. (1993). Some organizational consequences of CEO succession. Academy of Management Journal, 36(3), 644-659.

Milliken, F. J. (1990). Perceiving and interpreting environmental change: An examination of college administrators' interpretation of changing demographics. Academy of management Journal, 33(1), 42-63.

Mintzberg, H. (1983). Structures in five: Designing effective organizations. Englewood Cliffs, NJ: Prentice Hall.

Molnar, J. J., \& Rogers, D. L. (1976). Organizational effectiveness: An empirical comparison of the goal and system resource approaches. Sociological Quarterly, 17, 401-413.

Ocasio, W. (1994). Political dynamics and the circulation of power: CEO succession in U.S. industrial corporations, 1960-1990. Administrative Science Quarterly, 39(2), 285-312.

Osborn, R. N., Jauch, L. R., Martine, T., \& Glueck, W. F. (1981). The event of CEO succession, performance, and environmental conditions. Academy of Management Journal, 24, 183-191.

Ostrom, T. M. (1988). Computer simulation: The third symbol system. Journal of Experimental Social Psychology, 24, 381-392.

Pfeffer, J. (1982). Organizations and organization theory. Marshfield, MA: Pitman.

Pfeffer, J. (1993). Barriers to the advance of organizational science: Paradigm development as a dependent variable. Academy of Management Review, 18(4), 599-620.

Pfeffer, J., \& Davis-Blake, A. (1986). Administrative successions and organizational performance: How administrator experience mediates the succession effect. Academy of Management Journal, 29(1), 72-83.

Pfeffer, J., \& Salancik, G. R. (1977). Organizational context and the characteristics and tenure of hospital administrators. Academy of Management Journal, 20, 74-88.

Pfeffer, J., \& Salancik, G. R. (1978). The external control of organization. New York: Harper and Row.

Phelan, S., \& Lin, Z. (2001). Promotion systems and organizational performance: A contingency model. Computational and Mathematical Organization Theory, 7(3), 207-232.

Powell, W. W., \& DiMaggio, P. J. (1991). The new institutionalism in organizational analysis. Chicago: University of Chicago Press.

Price, J. L. (1968). Organizational effectiveness. Homewood, IL: Irwin.

Pugh, D. S., Hickson, D. T., Hinings, C. R., MacDonald, K. M., Turner, C., \& Lupton, T. (1963). A conceptual scheme for organizational analysis. Administrative Science Quarterly, 8, 289315 .

Reinganum, M. R. (1985). The effect of executive succession on stockholder wealth. Administrative Science Quarterly, 30, 46-60.

Rousseau, D. M., \& House, R. J. (1994). Meso organizational behavior: Avoiding the fundamental biases. Journal of Organizational Behavior, 1, 13-30.

Samuelson, B. A., Galbraith, C. S., \& McGuire, J. W. (1985). Organizational performance and top management turnover. Organization Studies, 6, 275-291.

Schoonhoven, C. B. (1981). Problems with contingency theory: Testing assumptions hidden within the language of contingency theory. Administrative Science Quarterly, 26, 349-370.

Schwartz, K. B., \& Menon, K. (1985). Executive succession in failing firms. Academy of Management Journal, 28, 680-686.

Scott, W. R. (1987). Organizations: Rational, natural, and open systems. Englewood Cliffs, NJ: Prentice Hall.

Simon, H. A. (1947). Administrative behavior. New York: Free Press.

Simon, H. A. (1962). The architecture of complexity. Proceedings of the American Philosophical Society, 106(6), 467-482. 
Simon, H. A. (1973). Applying information technology to organizational design. Public Administrative Review, 33(3), 268-278.

Singh, J. V., House, R. J., \& Tucker, D. J. (1986). Organizational change and organizational mortality. Administrative Science Quarterly, 31, 587-611.

Singh, J. V., Tucker, D. J., \& House, R. J. (1986). Organizational legitimacy and liability of newness. Administrative Science Quarterly, 31(2), 171-193.

Smith, M., \& White, M. C. (1987). Strategy, CEO specialization, and succession. Administrative Science Quarterly, 32(2), 263-280.

Taber, C. S., \& Timpone, R. J. (1996). Computational modeling. Thousand Oaks, CA: Sage.

Thompson, J. D. (1967). Organizations in action. New York: McGraw-Hill.

Thompson, M. B. (1994). Expanding simulation beyond planning and design. Industrial Engineering, 26(10), 64-66.

Tushman, M. L., \& Rosenkopf, L. (1996). Executive succession, strategic orientation and performance growth: A longitudinal study in the U.S. cement industry. Management Science, 42(7), 939-953.

Virany, B., Tushman, M., \& Romanelli, E. (1992). Executive succession and organization outcomes in turbulent environments: An organizational learning approach. Organization Science, 3, 72-91.

Weick, K. E. (1979). The social psychology of organizing. Reading, MA: Addison-Wesley.

Weiner, N., \& Mahoney, T. (1981). A model of corporate performance as a function of environmental, organizational, and leadership influences. Academy of Management Journal, 24, 453-470.

Weiss, G. (Ed.). (1999). Multiagent systems: A modern approach to distributed artificial intelligence. Cambridge, MA: MIT Press.

White, M. C., Smith, M., \& Barnett, T. (1997). CEO succession: Overcoming forces of inertia. Human Relations, 50(7), 805-828.

Wiersema, M. F. (1992). Strategic consequences of executive succession within diversified firms. Journal of Management Studies, 29(1), 73-94.

Worrell, D. L., \& Davidson, W. N., III. (1987). The effect of CEO succession on stockholder wealth in large firms following the death of the predecessor. Journal of Management, 13(3), 509-515.

Worrell, D. L., Davidson, W. N., III, Chandy, P. R., \& Garrison, S. L. (1988). Management turnover through deaths of key executives: Effects on investor wealth. Academy of Management Journal, 29(4), 674-694.

Worrell, D. L., Davidson, W. N., III, \& Glascock, J. L. (1993). Stockholder reactions to departures and appointments of key executives attributable to firings. Academy of Management Journal, 36(2), 387-401.

Zajac, E. J. (1990). CEO selection, succession, compensation and firm performance: A theoretical integration and empirical analysis. Strategic Management Journal, 11(3), 217-230.

Zucker, L. G. (1986). Production of trust: Institutional sources of economic structure, 18401920. In B. M. Staw \& L. L. Cummings (Eds.), Research in organizational behavior (Vol. 8, pp. 53-111). Greenwich, CT: JAI.

Zhiang ("John") Lin, with a Ph.D. in organizations and policy analysis from Carnegie Mellon University, is an associate professor of organizations, strategy, and international management at the School of Management, University of Texas at Dallas. His research interests mainly lie in the area of computational organization theory and its 


\section{GROUP \& ORGANIZATION MANAGEMENT}

applications to broad management issues ranging from organizational design and restructuring and strategic networking to international organizations.

Dan ("Lydia") Li is a doctoral candidate of organizations, strategy, and international management at the School of Management, University of Texas at Dallas. Her research interests mainly lie in the areas of strategic management and organization theory, with focuses on strategic networking, governance structures, and computational modeling. 